\title{
Polyostotic Fibrous Dysplasia Mimicking Osseous Metastases
}

\author{
Luwei Tao $^{1}$, Jingxin Sun ${ }^{1}$, Akriti Jain ${ }^{1}$, Jie Ouyang ${ }^{2}$, Daniel Tambunan ${ }^{1}$ \\ 1. Internal Medicine, Florida Hospital, Orlando, USA 2. Pathology, Florida Hospital, Orlando, USA
}

Corresponding author: Luwei Tao, taoluwei@gmail.com

\begin{abstract}
Fibrous dysplasia (FD) is a benign bone disorder, in which normal bone structure is replaced by fibrous connective tissue. Polyostotic FD is also related to McCune-Albright syndrome with possible endocrine disorder and Cafe-au-lait macules. Although FD commonly presents as craniofacial bone abnormality, atypical presentation can be misleading and pose a difficulty in clinical diagnosis. Here we report a case of polyostotic $\mathrm{FD}$, who presented as an accidental finding of multiple spinal osseous lesions, leading to clinic workup for metastatic cancer.
\end{abstract}

Categories: Endocrinology/Diabetes/Metabolism, Medical Education, Oncology Keywords: fibrous dysplasia, polyostotic, neoplasm

\section{Introduction}

Fibrous dysplasia (FD) is a rare non-neoplastic bone disorder featured by replacement of bone with fibrous connective tissue, which causes thinning of cortical bone, deformity, chronic pain and nerve compression [1]. The pathogenesis of FD involves mutation of GNAS1 gene and constitutive activation of G proteins, leading to proliferation of mesenchymal cells [2]. FD accounts for 5-7\% of all benign bone lesions [1]. Depending on the number of bones involved, FD can be monostotic or polyostotic. While monostotic lesions usually arrest with onset of puberty, polyostotic lesions continue to progress through adulthood [1,2]. The classic triad of McCune-Albright syndrome includes polyostotic FD (PFD), Cafe-au-lait macules and endocrinopathy. First symptoms of FD usually appear between 5 and 20 years of age and craniofacial skeleton abnormalities, including bone deformity and cranial nerve impingement, are common initial presentations $[1,3]$. Here we report a rare case of PFD, which initially presented with accidental findings of multiple spinal bone lesions, mimicking metastatic cancer.

Received 11/23/2018

Review began 12/17/2018 Review ended 12/25/2018 Published 01/14/2019

๑) Copyright 2019

Tao et al. This is an open access article distributed under the terms of the Creative Commons Attribution License CC-BY 3.0., which permits unrestricted use, distribution, and reproduction in any medium, provided the original author and source are credited.

\section{Case Presentation}

A 19-year-old male presented to our emergency room with one day history of left flank pain and dysuria. He endorsed mild chronic mild low back pain, which did not impair his daily activities and which he attributed to a previous car accident. During initial workup for hematuria, abdominal computed tomography (CT) scan revealed diffuse lumbar spinal osseous lesions with both osteoblastic and osteolytic features (Figure 1). The patient was therefore admitted to internal medicine service for workup of potential metastatic malignancy. His grandmother had cervical cancer; otherwise his family history was unremarkable. Physical examination showed mild tenderness to palpation on thoracic and lumbar spine. His right orbital rim was slightly more prominent than left side and there was a dark skin mark on right front thigh along L1-2 distribution (Figure 2). 


\section{Cureus}

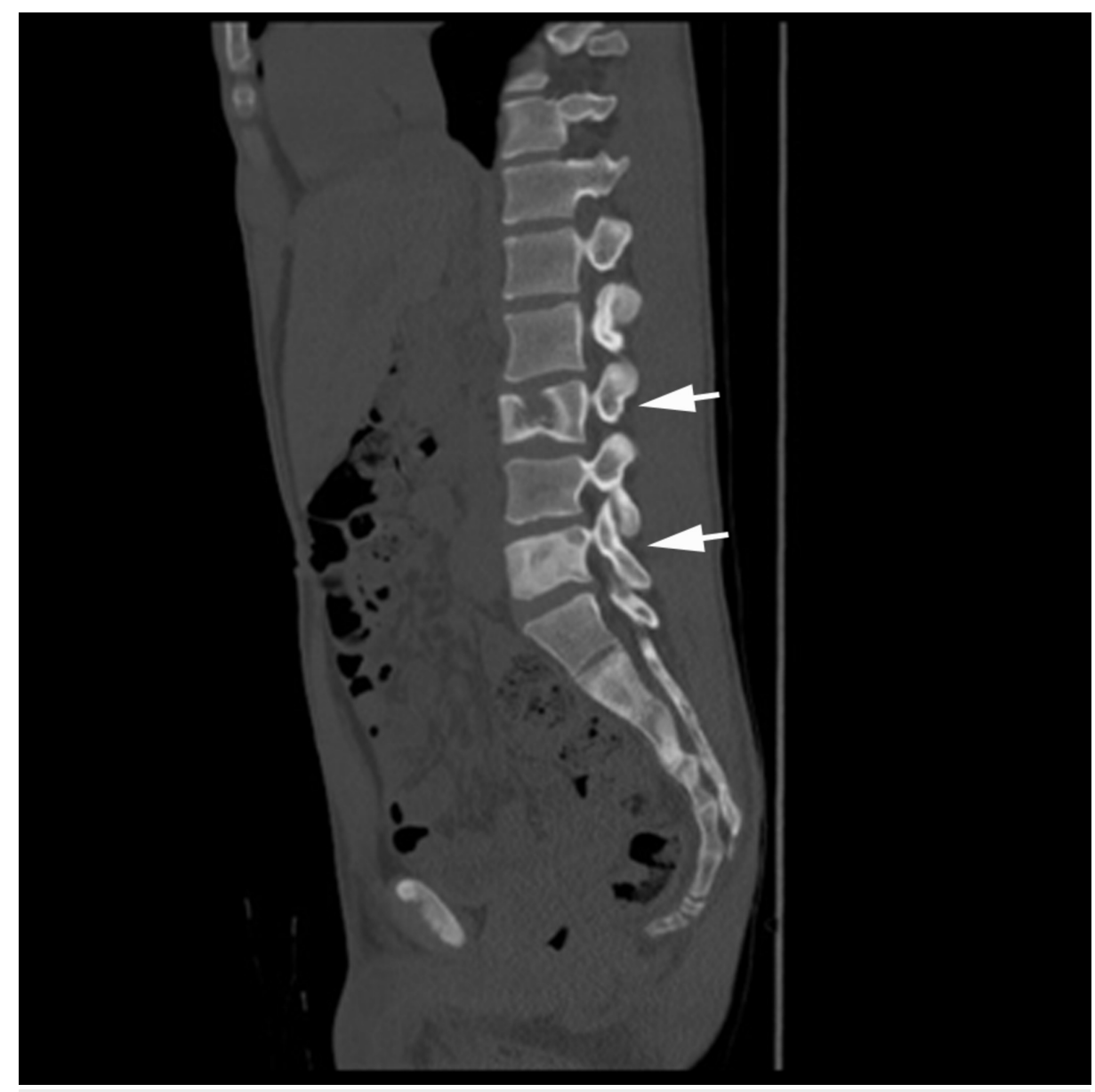

FIGURE 1: Admission computed tomography (CT) abdomen showed multiple osseous lesions with both osteosclerotic and osteolytic features as indicated by arrows. 


\section{Cureus}

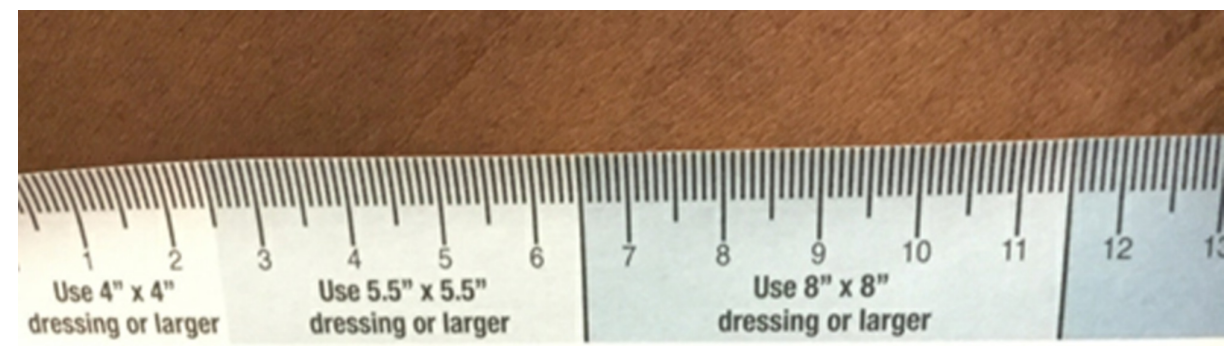

If the horizontal and vertical measurements of the wound (including redness/ir fall within the corresponding lines then use the dressing size indicatec

(II) ConvaTec

\section{Wound Measuring Guide}

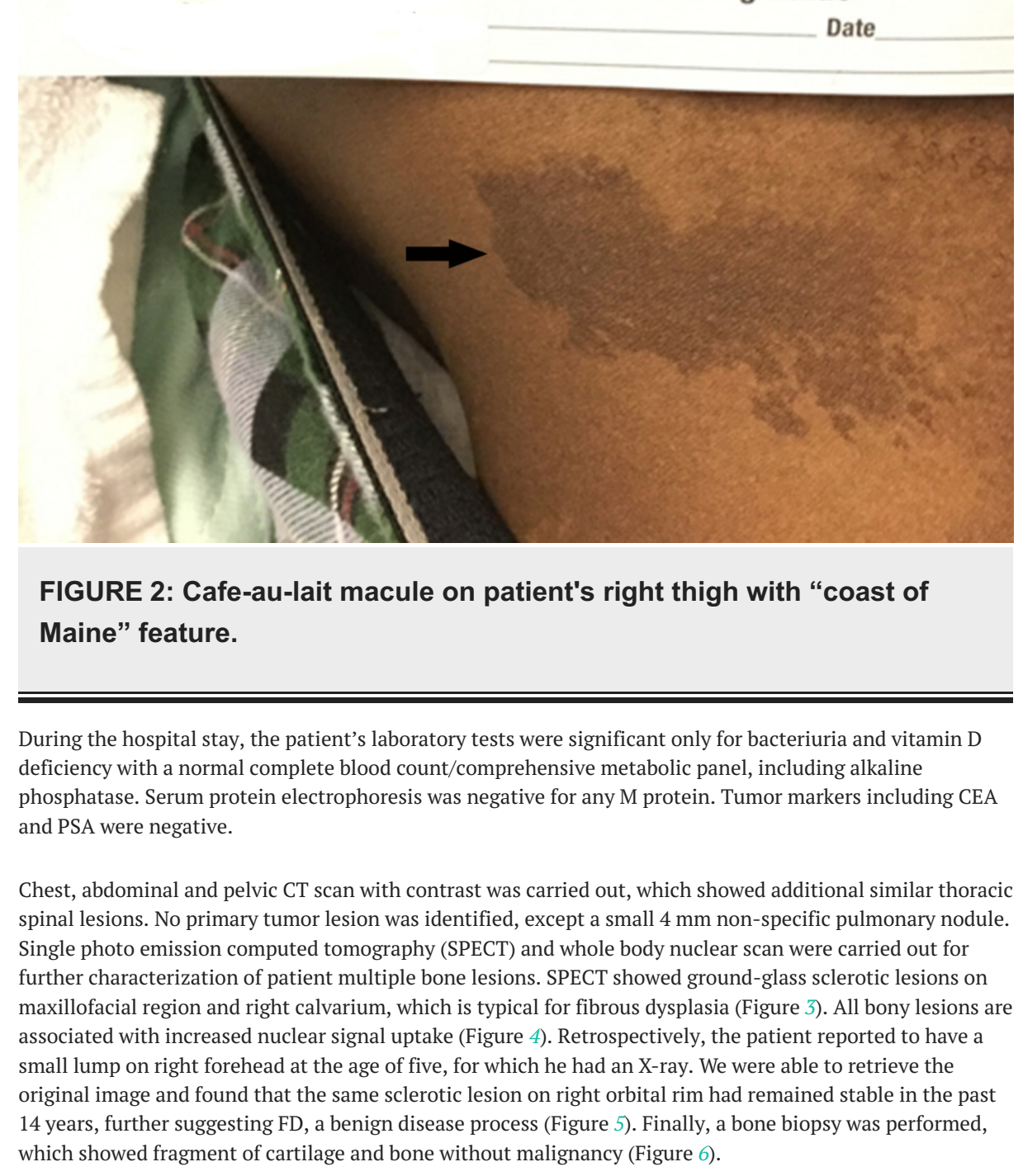




\section{Cureus}

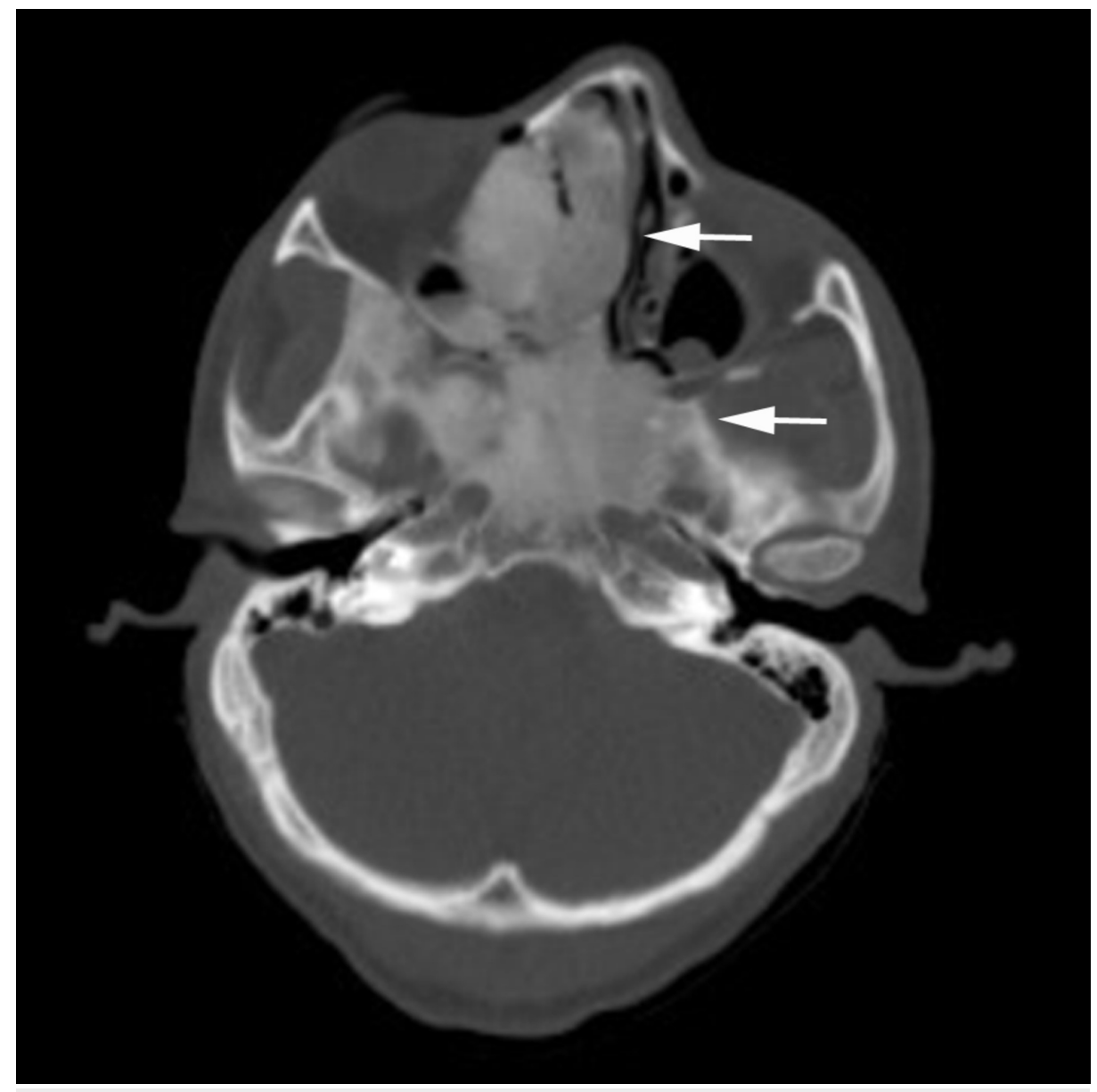

FIGURE 3: Single photo emission computed tomography (SPECT) head showed typical para-orbital and para-nasal ground-glass lesions as indicated by arrows. 


\section{Cureus}

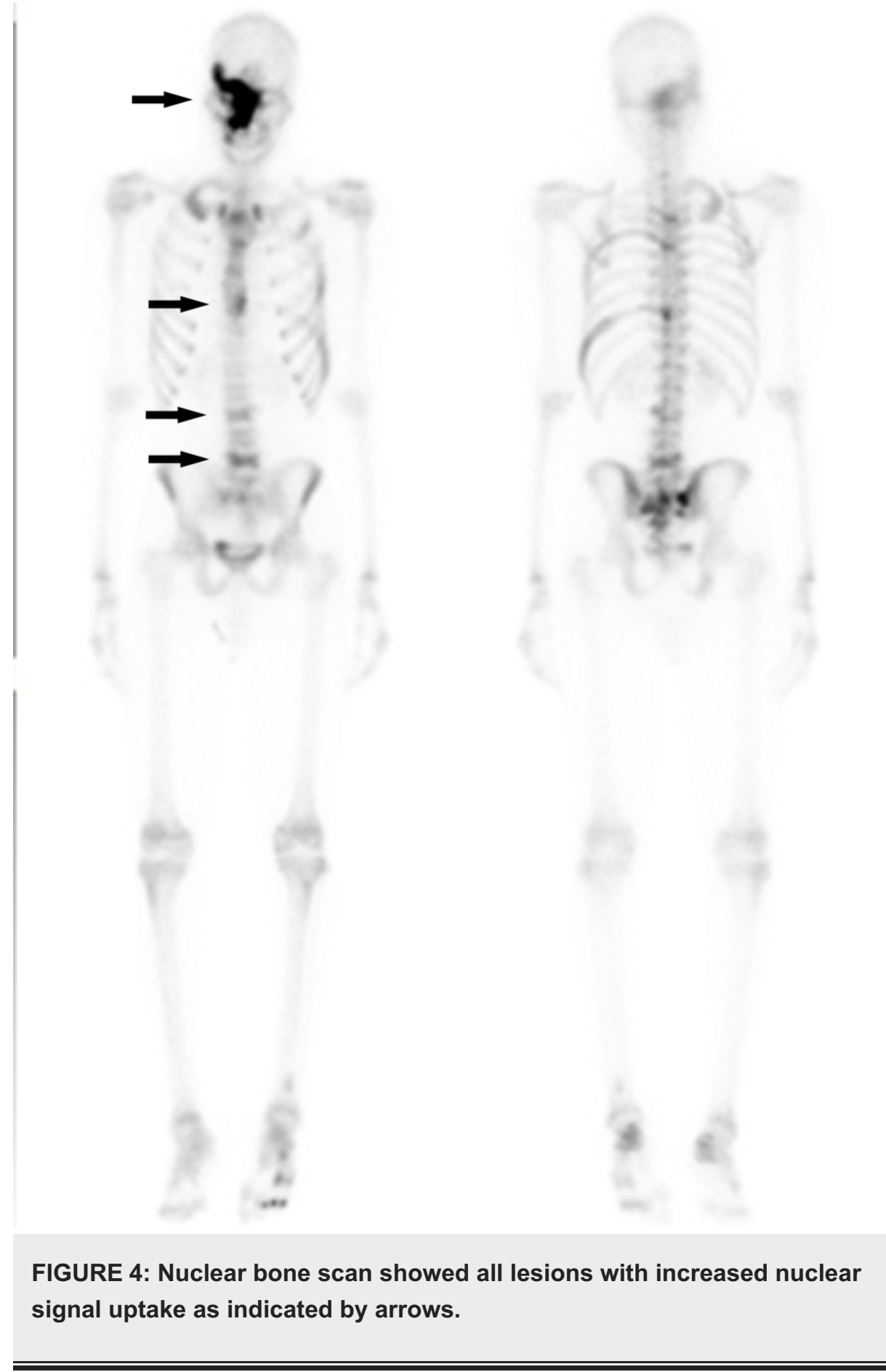




\section{Cureus}

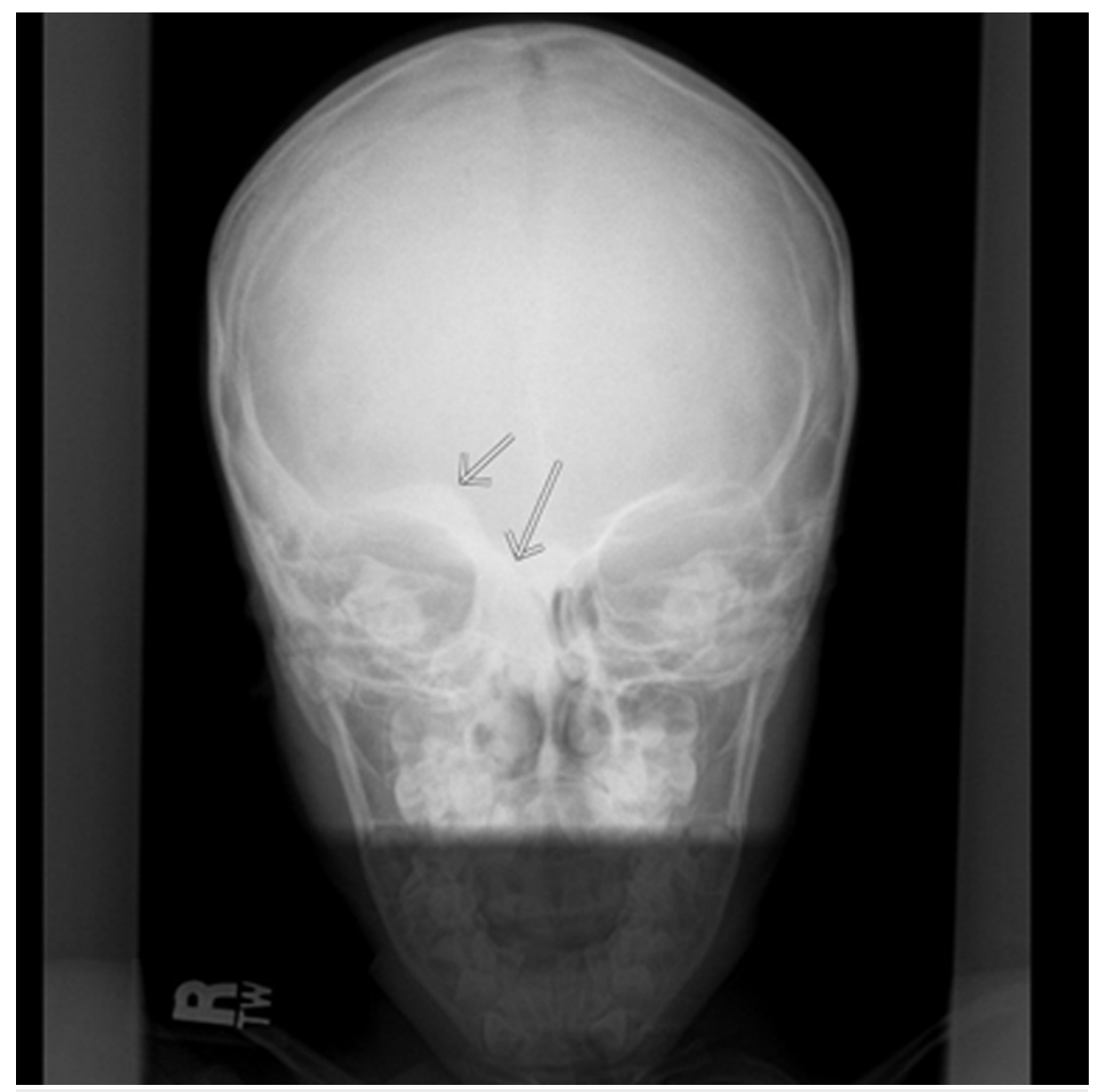

FIGURE 5: Skull X-ray of the same patient at five years of age with sclerotic lesion on right orbital rim as indicated by arrows.

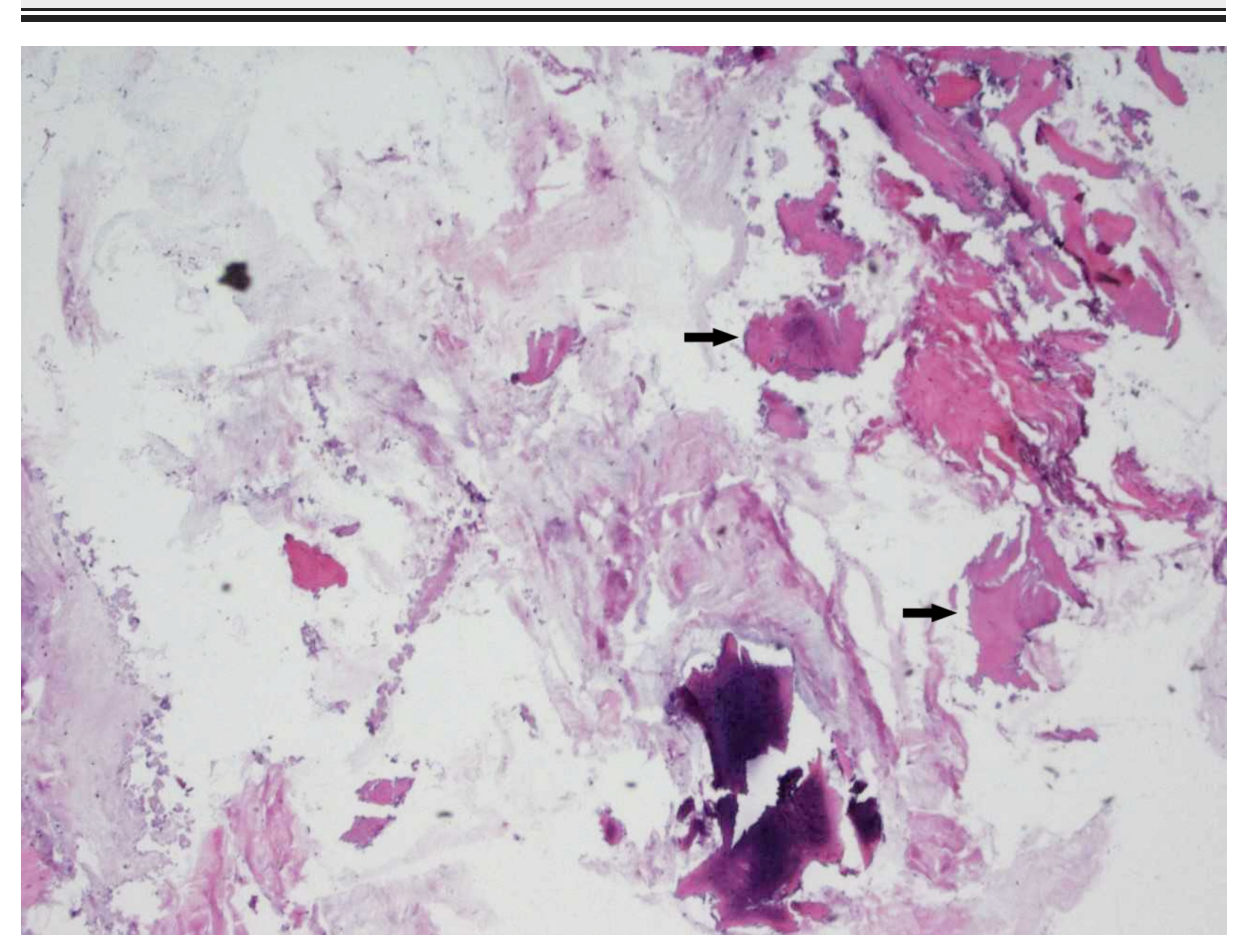

FIGURE 6: Bone biopsy showed fragment of cartilage and bone as indicated by arrows. No malignancy was identified. 
Based on clinical presentation and imaging, this patient was considered to have PFD with possible McCuneAlbright syndrome, although there was no sign of endocrinopathy yet. The patient was discharged with calcium and vitamin D supplements. Intermittent low dose acetaminophen or non-steroid antiinflammatory drugs (NSAIDs) were recommended for symptomatic relief of mild lower back pain. Consultation for surveillance of future endocrine disorder was also provided before the patient was discharged.

\section{Discussion}

FD is a rare skeletal disorder, which is often encountered in adolescents and young adults during the investigation for an unrelated cause. Clinical manifestation of FD varies greatly, depending on the affected skeleton $[4,5]$. Painless bony enlargement of part of the face is the usual presentation in the first decade of patient's life. If bone structures of skull base or posterior orbit are involved, the patient can develop vision loss, hearing impairment or nerve palsy [5, 6]. It is important to recognize that PFD can also present with multiple bone sclerotic/lytic lesions, especially in young patients. Early clinical suspicion can accelerate diagnosis and minimize patient's anxiety. Differential diagnosis includes other common etiologies, such as multiple myeloma, prostate cancer, myeloproliferative disorders and infection. СT is the choice of initial evaluation [6]. Typical lesions have "ground-glass appearance" (Figure 3). Magnetic resonance imaging (MRI) can be used to visualize nearby structural compression. And positron emission tomography (PET)-CT, usually as a part of metastasis workup, shows high nuclear signal enrichment [7]. Bone biopsy is often necessary and confirmatory, especially when there is a concern for malignancy as in our case $[7,8]$.

PFD can be associated with skin cafe-au-lait pigmentation, endocrine abnormality, and this classic triad is known as McCune-Albright syndrome (MAS), which is caused by genetic mutation of GNAS gene. In contrast to cafe-au-lait spots with smooth borders in other disorders, the borders of cafe-au-lait spots in MAS are often irregular and described as coast of Maine (Figure 2). Girls with MAS may show precocious puberty caused by excessive estrogen. Less commonly, boys with MAS may also have early puberty, which is absent in this reported case. Endocrine problems may also affect other organs, including thyroid gland, pituitary gland and, rarely, adrenal gland. Patients need to be advised to have regular check up for potential endocrine disorders.

The treatment of polyostotic FD focuses on symptomatic control. Pain is common among FD patients. Some patients require NSAIDS for pain control with or without narcotics. The use of bisphosphonates for pain control has been reported. In small non-randomized trials, intravenous infusion of pamidronate is associated with reduced bone pain, decreased bone turnover, reduced fracture and increased bone density [ 9 , 10]. However, it is controversial whether bisphosphonates can change progression of the disease process [11, 12]. For patients who failed the treatment with bisphosphonates, the use of denosumab has also been reported [13]. Surgical intervention is usually necessary for lesions which are cosmetically significant or symptomatic [6]. For patients with clinical impairment of optic nerve, urgent surgical decompression is indicated [14]. However, for asymptomatic patients with radiographical involvement of optic nerve, watchful waiting showed superior clinical outcome and prophylactic surgical decompression is not indicated [14].

\section{Conclusions}

Fibrous dysplasia is a rare benign bone disorder featured with replacement of bone with fibrous connective tissue, which can mimic metastatic bone disease. It is important to recognize that PFD can also present with multiple osseous lesions, especially in young patients. Early clinic suspicion can accelerate diagnosis, minimize unnecessary workup, cost and length of stay.

\section{Additional Information \\ Disclosures}

Human subjects: Consent was obtained by all participants in this study. Conflicts of interest: In compliance with the ICMJE uniform disclosure form, all authors declare the following: Payment/services info: All authors have declared that no financial support was received from any organization for the submitted work. Financial relationships: All authors have declared that they have no financial relationships at present or within the previous three years with any organizations that might have an interest in the submitted work. Other relationships: All authors have declared that there are no other relationships or activities that could appear to have influenced the submitted work.

\section{References}

1. Saglik Y, Atalar H, Yildiz Y, Basarir K, Erekul S: Management of fibrous dysplasia. A report on 36 cases . Acta Orthop Belg. 2007, 73:96-101.

2. Penn DL, Tartarini RJ, Glass CH, De Girolami U, Zamani AA, Dunn IF: Natural history of cranial fibrous dysplasia revealed during long-term follow-up: case report and literature review. Surg Neurol Int. 2017, 8:209. 10.4103/sni.sni 7 17

3. Majoor BC, Appelman-Dijkstra NM, Fiocco M, van de Sande MA, Dijkstra PS, Hamdy NA: Outcome of long- 
term bisphosphonate therapy in McCune-Albright syndrome and polyostotic fibrous Dysplasiad. J Bone Miner Res. 2017, 32:264-276. 10.1002/jbmr.2999

4. Couturier A, Aumaitre O, Gilain L, Jean B, Mom T, Andre M: Craniofacial fibrous dysplasia: a 10-case series. Eur Ann Otorhinolaryngol Head Neck Dis. 2017, 134:229-235. 10.1016/j.anorl.2017.02.004

5. Thomsen MD, Rejnmark L: Clinical and radiological observations in a case series of 26 patients with fibrous dysplasia. Calcif Tissue Int. 2014, 94:384-395. 10.1007/s00223-013-9829-0

6. Lee JS, FitzGibbon EJ, Chen YR, et al.: Clinical guidelines for the management of craniofacial fibrous dysplasia. Orphanet J Rare Dis. 2012, 7:2. 10.1186/1750-1172-7-S1-S2

7. Clark J, Carson W: A case of craniofacial polyostotic fibrous dysplasia . J Radiol Case Rep. 2010, 4:1-6. 10.3941/jrcr.v4i9.330

8. Fitzpatrick KA, Taljanovic MS, Speer DP, Graham AR, Jacobson JA, Barnes GR, Hunter TB: Imaging findings of fibrous dysplasia with histopathologic and intraoperative correlation. AJR Am J Roentgenol. 2004, 182:1389-1398. 10.2214/ajr.182.6.1821389

9. Matarazzo P, Lala R, Masi G, Andreo M, Altare F, de Sanctis C: Pamidronate treatment in bone fibrous dysplasia in children and adolescents with McCune-Albright syndrome. J Pediatr Endocrinol Metab. 2002, 15:929-937.

10. Plotkin H, Rauch F, Zeitlin L, Munns C, Travers R, Glorieux FH: Effect of pamidronate treatment in children with polyostotic fibrous dysplasia of bone. J Clin Endocrinol Metab. 2003, 88:4569-4575. 10.1210/jc.2003030050

11. Chan B, Zacharin M: Pamidronate treatment of polyostotic fibrous dysplasia: failure to prevent expansion of dysplastic lesions during childhood. J Pediatr Endocrinol Metab. 2006, 19:75-80. 10.1515/JPEM.2006.19.1.75

12. Chao K, Katznelson L: Use of high-dose oral bisphosphonate therapy for symptomatic fibrous dysplasia of the skull. J Neurosurg. 2008, 109:889-892. 10.3171/JNS/2008/109/11/0889

13. Eller-Vainicher C, Rossi DS, Guglielmi G, et al.: Prompt clinical and biochemical response to denosumab in a young adult patient with craniofacial fibrous dysplasia. Clin Cases Miner Bone Metab. 2016, 13:253-256. 10.11138/ccmbm/2016.13.3.253

14. Amit M, Collins MT, FitzGibbon EJ, Butman JA, Fliss DM, Gil Z: Surgery versus watchful waiting in patients with craniofacial fibrous dysplasia--a meta-analysis. PLoS One. 2011, 6:25179.

10.1371/journal.pone.0025179 